\title{
Fractional anisotropy in the centrum semiovale as a quantitative indicator of cerebral white matter damage in the subacute phase in patients with carbon monoxide poisoning: correlation with the concentration of myelin basic protein in cerebrospinal fluid
}

\author{
Takaaki Beppu $\cdot$ Shunrou Fujiwara $\cdot$ Hideaki Nishimoto $\cdot$ \\ Atsuhiko Koeda $\cdot$ Shinsuke Narumi $\cdot$ Kiyoshi Mori $\cdot$ \\ Kuniaki Ogasawara $\cdot$ Makoto Sasaki
}

Received: 23 October 2011/Accepted: 26 December 2011/Published online: 19 January 2012

(C) The Author(s) 2012. This article is published with open access at Springerlink.com

\begin{abstract}
Carbon monoxide (CO) poisoning leads to demyelination of cerebral white matter (CWM) fibers, causing chronic neuropsychiatric symptoms. To clarify whether fractional anisotropy (FA) from diffusion tensor imaging in the centrum semiovale can depict demyelination in the CWM during the subacute phase after $\mathrm{CO}$ inhalation, we examined correlations between FA in the centrum semiovale and myelin basic protein (MBP) in cerebrospinal fluid. Subjects comprised 26 adult CO-poisoned patients $\leq 60$ years old. MBP concentration was examined for all patients at 2 weeks after $\mathrm{CO}$ inhalation. The mean FA of the centrum semiovale bilaterally at
\end{abstract}

T. Beppu $(\bowtie) \cdot$ S. Fujiwara $\cdot$ H. Nishimoto $\cdot$ K. Ogasawara Department of Neurosurgery, Iwate Medical University,

Uchimaru 19-1, Morioka 020-8505, Japan

e-mail: tbeppu@iwate-med.ac.jp

T. Beppu

Department of Hyperbaric Medicine, Iwate Medical University,

Uchimaru 19-1, Morioka 020-8505, Japan

A. Koeda

Department of Psychiatry, Iwate Medical University,

Uchimaru 19-1, Morioka 020-8505, Japan

S. Narumi

Department of Neurology, Iwate Medical University,

Uchimaru 19-1, Morioka 020-8505, Japan

K. Mori

Iwate Prefectural Advanced Critical Care and Emergency

Center, Morioka, Japan

M. Sasaki

Advanced Medical Research Center, Iwate Medical University,

Morioka, Japan
2 weeks was also examined for all patients and 21 agematched healthy volunteers as controls. After these examinations, the presence of chronic symptoms was checked at 6 weeks after $\mathrm{CO}$ poisoning. Seven patients displayed chronic symptoms, of whom six showed abnormal MBP concentrations. The remaining 19 patients presented no chronic symptoms and no abnormal MBP concentrations, with MBP concentrations undetectable in 16 patients. The MBP concentration differed significantly between patients with and without chronic symptoms. The mean FA was significantly lower in patients displaying chronic symptoms than in either patients without chronic symptoms or controls. After excluding the 16 patients with undetectable MBP concentrations, a significant correlation was identified between MBP concentration and FA in ten patients. The present results suggest that FA in the centrum semiovale offers a quantitative indicator of the extent of demyelination in damaged CWM during the subacute phase in CO-poisoned patients.

Keywords Carbon monoxide poisoning - Cerebral white matter fiber - Demyelination - Diffusion tensor imaging . Fractional anisotropy $\cdot$ Myelin basic protein

$\begin{array}{ll}\text { Abbreviation } \\ \text { CNS } & \text { Central nervous system } \\ \text { CSF } & \text { Cerebrospinal fluid } \\ \text { CO } & \text { Carbon monoxide } \\ \text { COHb } & \text { Carboxyhemoglobin } \\ \text { DNS } & \text { Delayed neuropsychiatric sequelae } \\ \text { DTI } & \text { Diffusion tensor imaging } \\ \text { FA } & \text { Fractional anisotropy } \\ \text { ADC } & \text { Apparent diffusion coefficient } \\ \text { GCS } & \text { Glasgow coma scale } \\ \text { MBP } & \text { Myelin basic protein }\end{array}$


MRI Magnetic resonance imaging

ROI Region of interest

T2WI T2-weighted magnetic resonance imaging

\section{Introduction}

Approximately $30 \%$ of patients surviving acute carbon monoxide (CO) poisoning display various chronic neuropsychiatric symptoms [31, 32]. Of these, approximately two-thirds demonstrate persistent neurological symptoms from the acute phase to the chronic phase. The remaining one-third show delayed neuropsychiatric sequelae (DNS), which are recurrent neuropsychiatric symptoms occurring after an interval of apparent normality ("lucid interval;" mean duration 22 days) following apparent recovery from acute symptoms [6, 33]. Animal experiments and some clinical studies have led to the hypothesis that damage after $\mathrm{CO}$ poisoning results from complicated mechanisms due to CO-mediated toxicity: mitochondrial oxidative stress in the central nervous system (CNS) following CO-induced tissue hypoxia [35]; perivascular oxidative stress mediated by intravascular neutrophil activation [26]; and alteration of myelin basic protein (MBP), a major myelin component in the CNS, due to lipid peroxygenation leading to autoimmunological demyelination of CNS [24, 25]. Autoimmunological demyelination induces further inflammation in the cerebral white matter (CWM) [31]. Gray matter structures, such as the cerebral cortex, basal ganglia and hippocampus, must be damaged by severe hypoxia, since these structures display higher cellular activity and higher oxygen requirements than white matter structures and are more vulnerable to oxygen deprivation [29]. However, damage in the CWM is seen in patients both with and without damage to gray matter structures, and the severity of CWM damage appears to correlate with prognosis in COpoisoned patients $[15,34]$.

Assessment of CWM damage caused by $\mathrm{CO}$ poisoning in the acute or subacute phase contributes to predictions of progress to DNS and prognosis of chronic symptoms, and appropriate triage of patients with $\mathrm{CO}$ poisoning for observation and treatment. Additional quantitative and objective examinations are desirable for assessment of CWM damage after $\mathrm{CO}$ poisoning. However, no universally accepted severity scale in routine examinations, such as level of consciousness or carboxyhemoglobin concentration, is available for assessing CWM damage caused by $\mathrm{CO}$ poisoning. This is because clinical features are largely affected by the degree of cellular hypoxia resulting from binding of $\mathrm{CO}$ to myoglobin rather than hemoglobin and may be markedly affected by various conditions before admission, such as the duration before hospitalization and the care provided before hospitalization $[7,12,20]$. As one of mechanisms for damage in CWM is auto-immunological demyelination, measuring the MBP concentration in the cerebrospinal fluid (CSF) has recently been proposed as an indicator for the extent of CWM damage after $\mathrm{CO}$ poisoning [11, 14]. However, detection of MBP using a lumbar tap is a highly invasive procedure and only indicates white-matter damage somewhere within the entire CNS. A less-invasive, objective and quantitative examination that could be used in place of measuring MBP is therefore desired. Diffusion tensor imaging (DTI), a magnetic resonance imaging (MRI) sequence, is potentially more sensitive for detecting demyelination in CWM. Among various quantitative parameters such as apparent diffusion coefficient (ADC) and eigenvalues derived from DTI, fractional anisotropy (FA) has been recognized as the most useful for evaluating the integrity of CWM fibers [2]. Indeed, FA is frequently used for evaluating the extent of damaged CWM fibers in patients with demyelinating diseases such as multiple sclerosis $[1,27]$. CO poisoning causes damage in various regions of the CWM, but the centrum semiovale has been considered a region more responsible for chronic neuropsychiatric symptoms after CO poisoning than other regions $[4,10,19,22]$. Herein, we measured FA from DTI at the centrum semiovale in COpoisoned patients, and evaluated the correlation between the FA and concentration of MBP in the CSF. This study aimed to clarify whether FA in the centrum semiovale offers a quantitative indicator of the extent of demyelination in damaged CWM during the subacute phase in COpoisoned patients.

\section{Methods}

Patients

All study protocols were approved by the Ethics Committee of Iwate Medical University, Morioka, Japan. Patients recruited to this study were admitted to Iwate Medical University Hospital between April 2008 and February 2011. Entry criteria for this study were: age $\geq 20$ but $\leq 60$ years in patients who had suffered from $\mathrm{CO}$ poisoning caused by a fire or charcoal burning; performance of DTI and measurement of MBP concentration according to the protocol in this study; no past history of brain disorders, including surgical operation, irradiation, stroke, infection or demyelinating disease; and provision of written informed consent to participate. Diagnosis was based on present history of exposure to $\mathrm{CO}$ and presence of acute neurological symptoms such as impairment of consciousness and headache on admission. After excluding patients 
who did not meet the entry criteria, 26 patients were enrolled. Mean duration from the scene of $\mathrm{CO}$ exposure to arrival at our institute was $5.0 \mathrm{~h}$ (range $0.3-81 \mathrm{~h}$ ). All patients were treated with hyperbaric oxygenation therapy $\left(\mathrm{HBO}_{2}\right)(60 \mathrm{~min}$ of $100 \%$ oxygen inhalation via mask at 2.8 atmospheres absolute) started within $24 \mathrm{~h}$ of admission. $\mathrm{HBO}_{2}$ was continued with a single daily session for a week excluding the weekend. $\mathrm{HBO}_{2}$ was further continued for 4-8 weeks in cases with persistent symptoms. If DNS occurred, $\mathrm{HBO}_{2}$ was restarted and continued until 2 months after $\mathrm{CO}$ exposure. $\mathrm{HBO}_{2}$ was discontinued upon patient request or when symptoms were sufficiently improved. Duration of $\mathrm{HBO}_{2}$ administration for all patients ranged from 1 to 60 sessions (mean 12 sessions). The day of $\mathrm{CO}$ inhalation was defined as day 1 in this study.

\section{Measurement of MBP concentration in CSF}

MBP concentration in the CSF was examined using a lumbar tap at 2 weeks after CO poisoning (between day 12 and day 16) for all patients. Obtained CSF was frozen at $-20^{\circ} \mathrm{C}$ within $1 \mathrm{~h}$ after lumbar tap, then the frozen CSF was transported on dry ice to an outside laboratory (SRL, Tokyo, Japan). MBP in the CSF was assayed and measured using a MBP ELISA kit (Cosmic Corp., Tokyo, Japan) immediately after arrival at the laboratory. If the assay was delayed for a long time, frozen CSF was stored at $-80^{\circ} \mathrm{C}$. An abnormal MBP concentration was defined as $\geq 102 \mathrm{pg} /$ $\mathrm{ml}$. When the level of MBP was below the limit of detection, the result from the laboratory was reported as $\mathrm{MBP} \leq 40 \mathrm{pg} / \mathrm{ml}$.

\section{DTI}

For all patients, DTI was also performed at 2 weeks (between day 12 and day 16) using a 3.0-T whole-body scanner (GE Yokogawa Medical Systems, Tokyo, Japan) and 8-channel coil. Measurements of FA and ADC were performed using data from DTI (repetition time, $10,000 \mathrm{~ms}$; echo time, $62 \mathrm{~ms}$; matrix $128 \times 128$; field of view, $240 \times 240 \mathrm{~mm}$; $4 \mathrm{~mm}$ thickness with $1.5 \mathrm{~mm}$ gap; 6 motion-probing gradient directions; b value, $1,000 \mathrm{~s} / \mathrm{mm}^{2}$ ). The region of interest (ROI) was manually placed in the bilateral centrums semiovale in the CWM on non-diffusion-weighted images (Fig. 1). FA and ADC were measured bilaterally at the centrum semiovale, using free MRIcro software (http://www.cabiatl.com/mricro/). The FA and ADC for each subject were determined as the mean of values measured twice by the same investigator (S.F.), who was blinded to clinical data. The second measurement was performed 1 week after the first test, using a different randomized order of measurements from the first test.

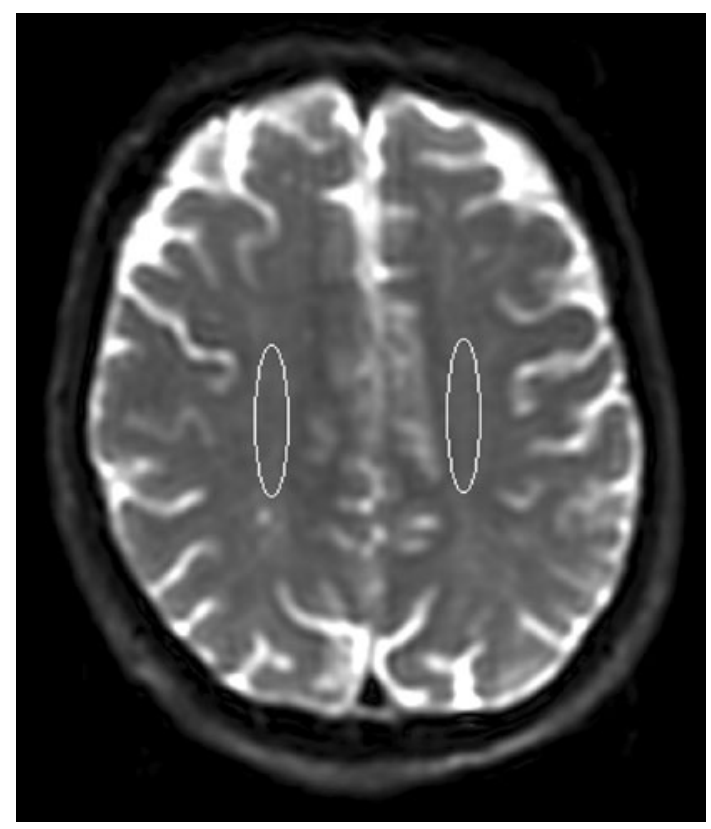

Fig. 1 Measurements of FA and ADC value at the centrum semiovale in a patient (case 7 in group S). Regions of interest (ROIs) were placed bilaterally on the centrum semiovale in non-diffusionweighted image

Finally, the mean FA and mean ADC values for the right and left centrum semiovale were calculated and defined as absolute values for each subject. The same procedures described above were performed for 21 age-matched healthy volunteers as controls (18 men, 3 women; mean age $41 \pm 10$ years, range $22-56$ years).

\section{Observation of symptoms}

Neurological symptoms were continuously observed for 6 weeks after admission using routine neurological examinations. Patients were assigned to one of two groups according to clinical behavior at 6 weeks (day 40-44) after $\mathrm{CO}$ poisoning: group $\mathrm{S}$, patients displaying neuropsychiatric symptoms; group A, patients showing asymptomatic status. Group $\mathrm{S}$ included both patients with symptoms persisting for 6 weeks and patients with DNS. DNS was defined as recurrent symptoms after apparent improvement of acute symptoms followed by a lucid interval. General intellectual function was also estimated using the minimental state examination (MMSE) [9] at 6 weeks after CO exposure. We defined the normal range, borderline range and dementia according to MMSE scores as $\geq 27, \leq 26$ but $\geq 22$, and $\leq 21$, respectively. When scores were considered borderline, patients with educational background $\geq 9$ years and evidence of obvious personality change according to interviews with family members were diagnosed with dementia. 
Statistical analyses

We statistically compared differences in mean age among group $\mathrm{S}$, group $\mathrm{A}$ and controls using the Mann-Whitney $U$ test. The incidence of abnormal $(\geq 102 \mathrm{pg} / \mathrm{ml}) \mathrm{MBP}$ concentration was compared between the two patient groups (group S and group A) using the $\chi^{2}$ for independence test. Mean FA and mean ADC values among two patients groups and controls were compared using the Mann-Whitney $U$ test. Intra-operator reliability for all absolute FA and ADC values was evaluated according to classification of the intra-class correlation coefficient (ICC) [21]. For $\operatorname{ICC}(1,1)$ and $\operatorname{ICC}(1, k)$ as intra-operator reliability, agreement of all absolute values between the first and second tests was analyzed for right and left lesions using one-factor analysis of variance. After excluding patients showing undetectable concentrations of MBP $(\leq 40 \mathrm{pg} / \mathrm{ml})$, the correlation between MBP and mean FA value was estimated using Spearman's correlation coefficient by rank test. Statistical significance was established at the $p<0.05$ level in all analyses.

\section{Results}

A total of 51 patients were admitted to our institute for treatment of CO poisoning between April 2008 and February 2011. After excluding 25 patients who did not meet the entry criteria for this study, a total of 26 patients ( 24 men, 2 women; mean age $40.1 \pm 11.4$ years) were enrolled. All patient data are summarized in Table 1. In 19 (73\%) of 26 patients, acute symptoms resolved completely within 4 days after admission, and no neuropsychiatric symptoms were present at 6 weeks from CO-inhalation (group A). The remaining seven patients (27\%) displayed chronic neuropsychiatric symptoms at 6 weeks (group S), including four patients with continuous persistence of symptoms for 6 weeks and three patients exhibiting DNS

Table 1 Summary of all patients

\begin{tabular}{|c|c|c|c|c|c|c|c|c|c|c|}
\hline Case & Group & Age & Etiology & $\begin{array}{l}\mathrm{COHb} \\
(\%)\end{array}$ & GCS & $\begin{array}{l}\mathrm{MBP} \\
(\mathrm{pg} / \mathrm{ml})\end{array}$ & $\begin{array}{l}\text { Mean } \\
\text { FA }\end{array}$ & $\begin{array}{l}\text { Mean } \\
\text { ADC }\end{array}$ & Main symptom at 6 weeks & $\begin{array}{l}\text { MMSE } \\
\text { score }\end{array}$ \\
\hline 1 & $\mathrm{~S}$ & 29 & Suicide & 24.8 & 11 & 252 & 0.345 & 0.622 & Dementia (persistent) & 23 \\
\hline 2 & $\mathrm{~S}$ & 57 & Suicide & 25.1 & 10 & 176 & 0.344 & 0.548 & Parkinsonism (persistent) & 27 \\
\hline 3 & $\mathrm{~S}$ & 38 & Suicide & 1.5 & 6 & 468 & 0.239 & 0.494 & Apallic syndrome (persistent) & NS \\
\hline 4 & $\mathrm{~S}$ & 55 & Suicide & 39.7 & 3 & 376 & 0.346 & 0.548 & Dementia (persistent) & 16 \\
\hline 5 & $\mathrm{~S}$ & 56 & Suicide & 13.5 & 11 & 130 & 0.338 & 0.584 & Akinetic mutism (DNS) & NS \\
\hline 6 & $\mathrm{~S}$ & 29 & Suicide & 3.6 & 14 & 99 & 0.353 & 0.498 & Parkinsonism (DNS) & 28 \\
\hline 7 & $\mathrm{~S}$ & 48 & Suicide & 28.6 & 6 & 110 & 0.317 & 0.565 & Dementia (DNS) & 23 \\
\hline 1 & $\mathrm{~A}$ & 22 & Suicide & 20.5 & 15 & 52.8 & 0.488 & 0.492 & None & 29 \\
\hline 2 & $\mathrm{~A}$ & 31 & Suicide & 47.3 & 13 & 40.6 & 0.354 & 0.494 & None & 30 \\
\hline 3 & A & 22 & Suicide & 9.3 & 12 & 63.6 & 0.447 & 0.555 & None & 30 \\
\hline 4 & $\mathrm{~A}$ & 47 & Heating & 33.3 & 14 & $\leq 40$ & 0.441 & 0.496 & None & 30 \\
\hline 5 & A & 44 & Heating & 13.7 & 15 & $\leq 40$ & 0.388 & 0.528 & None & 30 \\
\hline 6 & A & 26 & Suicide & 1.9 & 15 & $\leq 40$ & 0.395 & 0.504 & None & 30 \\
\hline 7 & A & 47 & Heating & 22.6 & 14 & $\leq 40$ & 0.393 & 0.551 & None & 29 \\
\hline 8 & A & 28 & Suicide & 19.2 & 15 & $\leq 40$ & 0.440 & 0.521 & None & 30 \\
\hline 9 & A & 41 & Suicide & 2.7 & 11 & $\leq 40$ & 0.381 & 0.487 & None & 30 \\
\hline 10 & A & 55 & Heating & 14.0 & 13 & $\leq 40$ & 0.366 & 0.504 & None & 30 \\
\hline 11 & A & 35 & Suicide & 25.3 & 8 & $\leq 40$ & 0.425 & 0.497 & None & 30 \\
\hline 12 & A & 56 & Suicide & 12.2 & 15 & $\leq 40$ & 0.395 & 0.501 & None & 30 \\
\hline 13 & A & 36 & Suicide & 44.1 & 12 & $\leq 40$ & 0.398 & 0.513 & None & 30 \\
\hline 14 & A & 34 & Suicide & 31.0 & 12 & $\leq 40$ & 0.394 & 0.530 & None & 30 \\
\hline 15 & A & 57 & Heating & 40.1 & 13 & $\leq 40$ & 0.400 & 0.541 & None & 30 \\
\hline 16 & A & 32 & Suicide & 19.3 & 10 & $\leq 40$ & 0.358 & 0.509 & None & 30 \\
\hline 17 & A & 34 & Suicide & 38.6 & 5 & $\leq 40$ & 0.406 & 0.535 & None & 30 \\
\hline 18 & A & 36 & Suicide & 23.5 & 10 & $\leq 40$ & 0.358 & 0.520 & None & 30 \\
\hline 19 & A & 48 & Suicide & 44.0 & 6 & $\leq 40$ & 0.352 & 0.539 & None & 30 \\
\hline
\end{tabular}

$\mathrm{COHb}$ and GCS indicate results of the initial examination

$\mathrm{COH} b$ carboxyhemoglobin, GCS Glasgow coma scale, $N S$ no study performed because of unconsciousness 
after apparent improvement of acute symptoms followed by a lucid interval. DNS in three patients occurred after DTI and measurement of MBP on day 21 in case 5, day 19 in case 6 and day 18 in case 7. Mean age was $45 \pm 12$ years in group $S, 38 \pm 11$ years in group $\mathrm{A}$ and $41 \pm 10$ years in controls. No significant differences in age were found between groups $\mathrm{S}$ and A $(p=0.24)$, between group $\mathrm{S}$ and controls $(p=0.51)$, or between group $\mathrm{A}$ and controls $(p=0.40)$.

In the seven patients in sroup $\mathrm{S}$, six showed abnormal MBP concentrations $(\geq 102 \mathrm{pg} / \mathrm{ml})$, and one patient showed a level of $99 \mathrm{pg} / \mathrm{ml}$. None of the 19 patients in group A showed abnormal concentrations of MBP, with 16 patients showing undetectable concentrations of MBP $(\leq 40 \mathrm{pg} / \mathrm{ml})$. The incidence of an abnormal MBP levels was statistically different between groups $\mathrm{P}$ and $\mathrm{A}$ $(p<0.001)$. MBP concentrations for the four patients with persistent symptoms in group $S$, for the three patients with DNS in group $\mathrm{S}$ and for the three patients in group A were more than $\geq 150 \mathrm{pg} / \mathrm{ml}$, around $100 \mathrm{pg} / \mathrm{ml}$ and around $50 \mathrm{pg} / \mathrm{ml}$, respectively (Table 1 ).

Table 2 shows ranges and means of FA and ADC for each group. The range of FA for group S slightly overlapped that for group A, but differed markedly from that for controls. Ranges of FA for group A and controls were similar. The mean FA for group $\mathrm{S}$ was significantly lower than those for group A $(p<0.001)$ and controls $(p<0.001)$, whereas no significant difference was found between group A and controls $(p=0.57)$ (Fig. 2a). In
Fig. 2a, individual mean FA values of the three patients with DNS were not obviously different from those of the four patients with persistent symptoms in group S. Group $S$ patients were clearly differentiated from group A patients at a cutoff of $0.353(100 \%$ sensitivity, $94.7 \%$ specificity) and from controls at a cutoff of $0.360(100 \%$ sensitivity, $100 \%$ specificity). On the other hand, the range of ADC in each group was similar, and the mean ADC did not differ significantly among any of the three groups (Fig. 2b). Intraoperator reliability for absolute FA was classified as "almost perfect" for the centrum semiovale bilaterally; $\operatorname{ICC}(1,1)$ and $\operatorname{ICC}(1, k)$ were 0.88 and 0.93 for the right side, and 0.95 and 0.98 for the left side, respectively. Intraoperator reliability for absolute ADC was also classified as "almost perfect" for bilateral centrum semiovale; $\operatorname{ICC}(1,1)$ and $\operatorname{ICC}(1, k)$ were 0.98 and 0.99 for the right side, and 0.91 and 0.95 for the left side, respectively.

After excluding 16 patients showing undetectable levels ( $\leq 40 \mathrm{pg} / \mathrm{ml}$ ), the ten remaining patients (all patients in groups $\mathrm{S}$ and 3 patients in group A) showed a strong correlation between the mean FA and MBP $(r=-0.79$, $p=0.02$ ) (Fig. 3).

\section{Discussion}

Ide et al. [11] have documented that MBP concentration in patients with DNS showed marked elevation around 2 weeks after $\mathrm{CO}$ poisoning, peaking at around 30 days.
Table 2 Range and mean value of FA and ADC for each group

\begin{tabular}{llllll}
\hline & FA & & & \multicolumn{2}{l}{ ADC $\left(\times 10^{-3} \mathrm{~mm}^{2} / \mathrm{s}\right)$} \\
\cline { 2 - 3 } \cline { 5 - 6 } & Range & Mean & & Range & Mean \\
\hline Group S & $0.239-0.353$ & $0.326 \pm 0.040$ & & $0.494-0.622$ & $0.551 \pm 0.045$ \\
Group A & $0.352-0.447$ & $0.395 \pm 0.029$ & & $0.487-0.601$ & $0.517 \pm 0.021$ \\
Controls & $0.363-0.445$ & $0.400 \pm 0.027$ & & $0.472-0.580$ & $0.517 \pm 0.023$ \\
\hline
\end{tabular}
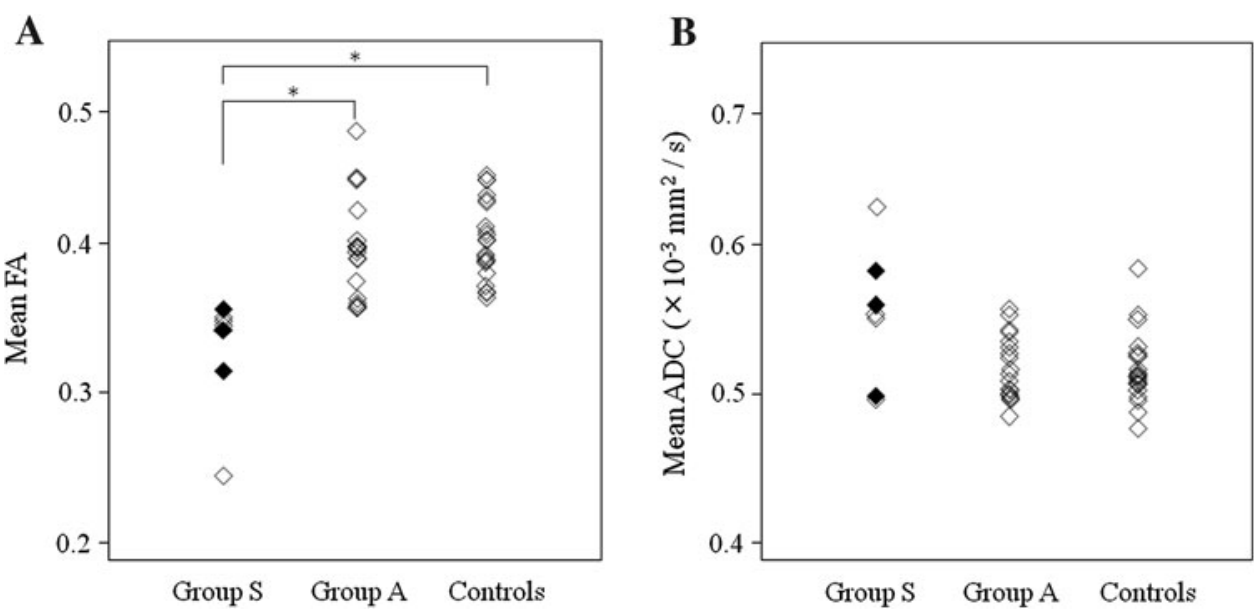


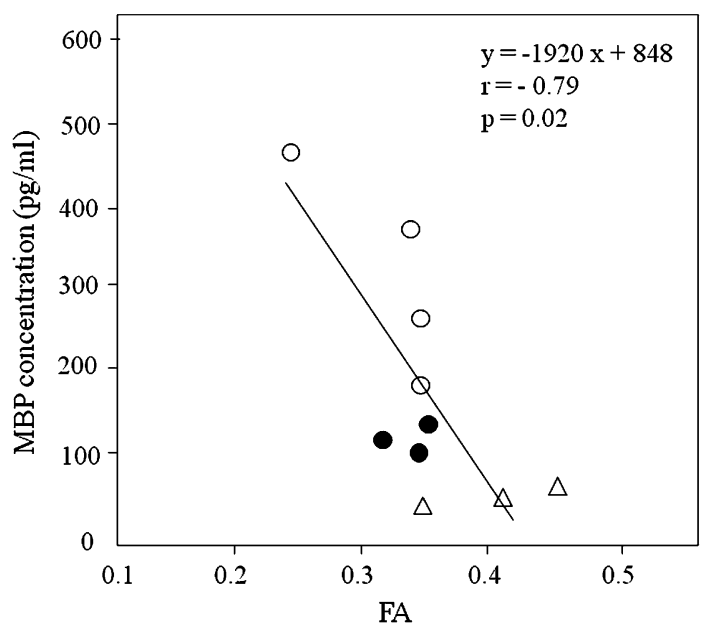

Fig. 3 Correlation between FA and MBP concentration in ten patients showing MBP concentration $>40 \mathrm{pg} / \mathrm{ml}$. White circle, patient with persistent chronic symptoms in group $\mathrm{S}$; black circle, patient with DNS in group $\mathrm{S}$; triangle, patient in group $\mathrm{A}$

The timing for MBP measurements in the present study was thus established at 2 weeks (between day 12 and day 16) after admission. As a result, the incidence of abnormal MBP concentration was significantly higher in patients with chronic neuropsychiatry symptoms (group S) than in patients without chronic symptoms (group A) or controls. These results suggest that patients in group $S$ certainly suffered from demyelinating changes somewhere in the CWM and support the theory that chronic neuropsychiatric symptoms after $\mathrm{CO}$ intoxication result from progressive demyelination in the CWM [24, 25]. The MBP concentration in case 6 was slightly lower $(99 \mathrm{pg} / \mathrm{ml})$ than the abnormal level, but the patient displayed akinetic mutism compatible with DNS at 1 week after measurement of MBP. The concentration of MBP in this patient might have been on the way to reaching abnormal levels, as demyelination of CWM in patients with DNS has been considered to undergo gradual progression during the lucid interval [13]. MBP concentrations of DNS patients were between those of patients with persistent symptoms in group $\mathrm{S}$ and those of patients in group A (Table 1; Fig. 3). These findings may indicate that demyelination begins to progress during the lucid interval before DNS. Although measuring MBP concentrations thus offers a useful indicator for assessing the extent of demyelination due to $\mathrm{CO}$ poisoning, detection of MBP using a lumbar tap is a highly invasive procedure and only indicates white-matter damage somewhere within the CNS.

Neuroimaging is minimally invasive and can visualize any region in the CWM. T2-weighted imaging (T2WI) often depicts abnormalities in the CWM in CO-poisoned patients. However, the interpretation of findings from routine MRI is difficult, as hyperintense foci in the CWM on T2WI can represent various progressive histological changes, including vasogenic edema, multiple necrosis, extensive axonal destruction and/or demyelination without axonal destruction $[4,12]$. We therefore performed DTI in the same period as detection of MBP, since DTI is potentially more sensitive for assessing the extent of demyelinating changes in the CWM than other MRI sequences. As progressive reduction of $\mathrm{FA}$ values with age has been reported [5], we compared patients $<60$ years old with agematched controls in this study. The finding of no significant difference in mean age among groups $\mathrm{S}$, group $\mathrm{A}$ and controls suggests a negligible contribution of aging to FA values in this study. Previous reports have documented damage in various regions of the $\mathrm{CWM}$ after $\mathrm{CO}$ poisoning $[8,18,28]$. Indeed, some studies have reported correlations between FA values in various regions of the CWM in the chronic phase and cognitive dysfunction among CO-poisoned patients with DNS [16, 23, 30]. However, the centrum semiovale in the CWM has been suggested as a key region responsible for chronic neurological symptoms [4, $10,19,22]$. A study using DTI at various phases after CO poisoning has also shown that FA in the centrum semiovale changes in parallel with cognitive impairments or neurological symptoms [17]. Based on these reports, we placed the ROI on the centrum semiovale to measure FA and ADC from DTI. As a result, mean FA for group S presenting with chronic neuropsychiatric symptoms was significantly lower than that for group A presenting with no chronic symptoms or that for controls consisting of healthy volunteers, whereas no significant difference was evident between group A and controls. In contrast, mean ADC did not differ significantly among the three groups. FA must be more sensitive for detecting CWM damage than ADC. Furthermore, these findings suggest that white matter fibers in the centrum semiovale were demyelinated in the subacute phase ( 2 weeks after poisoning) in CO-poisoned patients presenting with chronic symptoms. Notably, reductions in FA, suggestive of demyelination, were already present in the centrum semiovale before the recurrence of symptoms in the three patients with DNS. The reliability of this finding is supported by the result that MBP concentrations in DNS patients showed greater increases than those in group A patients at 2 weeks. These findings indicate the possibility of using FA in the centrum semiovale as an appropriate examination for predicting DNS during the lucid interval.

Our pilot study of DTI for CO-poisoned patients showed that FA enables representation of damage to white matter fibers in the centrum semiovale of patients with chronic neuropsychiatric symptoms [3]. That report, however, failed to demonstrate any correlation between FA in the centrum semiovale and MBP concentration, presumably because of the small sample size. Although subject criteria 
were more strictly established in the present study than in our previous investigation, the greater number of subjects in this study allow us to show a linear correlation between FA and MBP in ten patients showing MBP concentrations $>40 \mathrm{pg} / \mathrm{ml}$. This finding validated the use of the centrum semiovale to represent various demyelinated lesions in the CWM, and FA in the centrum semiovale obviously offers a quantitative indicator of demyelination in $\mathrm{CO}$-poisoned patients with chronic neuropsychiatric symptoms.

Some limitations must be considered in the interpretation of the study results. First, FA in the centrum semiovale may not strictly mirror the amount of demyelination in the whole CWM, although FA in the centrum semiovale correlated with MBP concentration. In group S, FA values in the centrum semiovale of the three DNS patients were not clearly different from those of the four patients with persistent symptoms (Fig. 2a), whereas MBP seemed to allow differentiation between subgroups in group $\mathrm{S}$ (around $100 \mathrm{pg} / \mathrm{ml}$ in patients with DNS and $\geq 150 \mathrm{pg} / \mathrm{ml}$ in patients with persistent chronic symptoms). This discrepancy might hypothetically be explained if demyelinated lesions in patients with persistent symptoms vary more than those in DNS patients. FA measured in this study suggests the magnitude of demyelination in the centrum semiovale, whereas MBP concentration not only indicates the magnitude, but also the width of demyelination in the whole CNS. We think that FA in the centrum semiovale cannot allow differentiation of the severity of CWM damage among subjects including patients with DNS and those with persistent symptoms. Second, the chronic neuropsychiatric symptoms seen after $\mathrm{CO}$ poisoning may not be solely attributable to demyelinating changes in fibers of the centrum semiovale. However, knowing to the focus on the region of the CWM is obviously very useful when evaluating the extent of COinduced CWM damage using neuroimaging. We considered that the centrum semiovale represents the main region of damage and should be the focus of attention on neuroimaging in the subacute phase after CO poisoning [10]. Third, the sample size in this study was still small, with markedly fewer subjects in group $\mathrm{S}$ than in group $\mathrm{A}$. The small number of DNS patients resulted in difficulties with statistical comparisons between subgroups in group $\mathrm{S}$ and other groups. However, the small sample size resulted from the strict entry criteria for this study. Furthermore, we did not select subjects with any bias other than the criteria established for this study. Indeed, percentages for patients with and without chronic symptoms in this study were in agreement with the results of previous reports $[6$, 33]. Fourth, findings in this study cannot be applied to patients over 60 years old. In senior patients, FA values may be overestimated as aging may lead to reduced FA values.

\section{Conclusions}

This is the first report to find that FA in the CWM correlates with MBP concentrations in the CSF during the subacute phase in CO-poisoned patients. The identification of a significant negative correlation between FA in the centrum semiovale and MBP concentration validates the concept that the centrum semiovale can reveal various demyelinated lesions in the CWM and that FA in the centrum semiovale offers a quantitative indicator of demyelination in CO-poisoned patients with chronic neuropsychiatric symptoms.

Acknowledgments This study was supported in part by a Grant-inAid for Scientific Research (C) and for the Strategic Medical Science Research Center for Advanced Medical Science Research from the Ministry of Science, Education, Sports and Culture, Japan.

\section{Conflicts of interest None.}

Open Access This article is distributed under the terms of the Creative Commons Attribution Noncommercial License which permits any noncommercial use, distribution, and reproduction in any medium, provided the original author(s) and source are credited.

\section{References}

1. Bammer R, Augustin M, Strasser-Fuchs S, Seifert T, Kapeller P, Stollberger R, Ebner F, Hartung HP, Fazekas F (2000) Magnetic resonance diffusion tensor imaging for characterizing diffuse and focal white matter abnormalities in multiple sclerosis. Magn Reson Med 44:583-591

2. Beaulieu C (2002) The basis of anisotropic water diffusion in the nervous system - a technical review. NMR Biomed 15:435-455

3. Beppu T, Nishimoto H, Ishigaki D, Fujiwara S, Yoshida T, Oikawa H, Kamada K, Sasaki M, Ogasawara K (2010) Assessment of damage to cerebral white matter fiber in the subacute phase after carbon monoxide poisoning using fractional anisotropy in diffusion tensor imaging. Neuroradiology 52:735-743

4. Chang KH, Han MH, Kim HS, Wie BA, Han MC (1992) Delayed encephalopathy after acute carbon monoxide intoxication: MR imaging features and distribution of cerebral white matter lesions. Radiology 184:117-122

5. Charlton RA, Barrick TR, McIntyre DJ, Shen Y, O'Sullivan M, Howe FA, Clark CA, Morris RG, Markus HS (2006) White matter damage on diffusion tensor imaging correlates with agerelated cognitive decline. Neurology 66:217-222

6. Choi IS (1983) Delayed neurologic sequelae in carbon monoxide intoxication. Arch Neurol 40:433-435

7. Ernst A, Zibrak JD (1998) Carbon monoxide poisoning. N Engl J Med 339:1603-1608

8. Fan HC, Wang AC, Lo CP, Chang KP, Chen SJ (2009) Damage of cerebellar white matter due to carbon monoxide poisoning: a case report. Am J Emerg Med 27(757):e755-e757

9. Folstein MF, Folstein SE, McHugh PR (1975) "Mini-mental state". A practical method for grading the cognitive state of patients for the clinician. J Psychiatr Res 12:189-198

10. Fujiwara S, Beppu T, Nishimoto H, Sanjo K, Koeda A, Mori K, Kudo K, Sasaki M, Ogasawara K (2011) Detecting damaged regions of cerebral white matter in the subacute phase after carbon 
monoxide poisoning using voxel-based analysis with diffusion tensor imaging. Neuroradiology. doi:10.1007/s00234-011-0958-8

11. Ide T, Kamijo Y (2008) Myelin basic protein in cerebrospinal fluid: a predictive marker of delayed encephalopathy from carbon monoxide poisoning. Am J Emerg Med 26:908-912

12. Jain K (2009) Carbon monoxide and other tissue poisons. In: Jain KK (ed) Textbook of hyperbaric medicine, 5th edn. Hogrefe and Huber Publisher, Massachusetts, pp 43-133

13. Kado H, Kimura H, Murata T, Itoh H, Shimosegawa E (2004) Carbon monoxide poisoning: two cases of assessment by magnetization transfer ratios and $1 \mathrm{H}-\mathrm{MRS}$ for brain damage. Radiat Med 22:190-194

14. Kamijo Y, Soma K, Ide T (2007) Recurrent myelin basic protein elevation in cerebrospinal fluid as a predictive marker of delayed encephalopathy after carbon monoxide poisoning. Am J Emerg Med 25:483-485

15. Lapresle J, Fardeau M (1967) The central nervous system and carbon monoxide poisoning. II. Anatomical study of brain lesions following intoxication with carbon monixide (22 cases). Prog Brain Res 24:31-74

16. Lin WC, Lu CH, Lee YC, Wang HC, Lui CC, Cheng YF, Chang HW, Shih YT, Lin CP (2009) White matter damage in carbon monoxide intoxication assessed in vivo using diffusion tensor MR imaging. AJNR Am J Neuroradiol 30:1248-1255

17. Lo CP, Chen SY, Chou MC, Wang CY, Lee KW, Hsueh CJ, Chen CY, Huang KL, Huang GS (2007) Diffusion-tensor MR imaging for evaluation of the efficacy of hyperbaric oxygen therapy in patients with delayed neuropsychiatric syndrome caused by carbon monoxide inhalation. Eur J Neurol 14:777-782

18. O'Donnell P, Buxton PJ, Pitkin A, Jarvis LJ (2000) The magnetic resonance imaging appearances of the brain in acute carbon monoxide poisoning. Clin Radiol 55:273-280

19. Parkinson RB, Hopkins RO, Cleavinger HB, Weaver LK, Victoroff J, Foley JF, Bigler ED (2002) White matter hyperintensities and neuropsychological outcome following carbon monoxide poisoning. Neurology 58:1525-1532

20. Prockop LD, Chichkova RI (2007) Carbon monoxide intoxication: an updated review. J Neurol Sci 262:122-130

21. Shrout PE, Fleiss JL (1979) Intraclass correlations: uses in assessing rater reliability. Psychol Bull 86:420-428

22. Sohn YH, Jeong Y, Kim HS, Im JH, Kim JS (2000) The brain lesion responsible for parkinsonism after carbon monoxide poisoning. Arch Neurol 57:1214-1218
23. Terajima K, Igarashi $\mathrm{H}$, Hirose $M$, Matsuzawa $H$, Nishizawa $M$, Nakada T (2008) Serial assessments of delayed encephalopathy after carbon monoxide poisoning using magnetic resonance spectroscopy and diffusion tensor imaging on 3.0T system. Eur Neurol 59:55-61

24. Thom SR (1990) Carbon monoxide-mediated brain lipid peroxidation in the rat. J Appl Physiol 68:997-1003

25. Thom SR, Bhopale VM, Fisher D, Zhang J, Gimotty P (2004) Delayed neuropathology after carbon monoxide poisoning is immune-mediated. Proc Natl Acad Sci USA 101:13660-13665

26. Thom SR, Bhopale VM, Han ST, Clark JM, Hardy KR (2006) Intravascular neutrophil activation due to carbon monoxide poisoning. Am J Respir Crit Care Med 174:1239-1248

27. Tievsky AL, Ptak T, Farkas J (1999) Investigation of apparent diffusion coefficient and diffusion tensor anisotrophy in acute and chronic multiple sclerosis lesions. AJNR Am J Neuroradiol 20:1491-1499

28. Uchino A, Hasuo K, Shida K, Matsumoto S, Yasumori K, Masuda K (1994) MRI of the brain in chronic carbon monoxide poisoning. Neuroradiology 36:399-401

29. Valk J, van der Knaap MS (1992) Toxic encephalopathy. AJNR Am J Neuroradiol 13:747-760

30. Vila JF, Meli FJ, Serqueira OE, Pisarello J, Lylyk P (2005) Diffusion tensor magnetic resonance imaging: a promising technique to characterize and track delayed encephalopathy after acute carbon monoxide poisoning. Undersea Hyperb Med 32:151-156

31. Weaver LK (2009) Clinical practice. Carbon monoxide poisoning. N Engl J Med 360:1217-1225

32. Weaver LK, Hopkins RO, Chan KJ, Churchill S, Elliott CG, Clemmer TP, Orme JF Jr, Thomas FO, Morris AH (2002) Hyperbaric oxygen for acute carbon monoxide poisoning. N Engl J Med 347:1057-1067

33. Weaver LK, Hopkins RO, Elliott G (1999) Carbon monoxide poisoning. N Engl J Med 340:1290 Author reply 1292

34. Zagami AS, Lethlean AK, Mellick R (1993) Delayed neurological deterioration following carbon monoxide poisoning: MRI findings. J Neurol 240:113-116

35. Zhang J, Piantadosi CA (1992) Mitochondrial oxidative stress after carbon monoxide hypoxia in the rat brain. J Clin Invest 90:1193-1199 